\title{
Changes in blood lead concentrations in women in Wales 1972-82
}

\author{
P C ELWOOD
}

\begin{abstract}
Blood lead concentrations, estimated in epidemiological surveys of adult women in Wales, have shown a fall of over $30 \%$ since 1972 . During the same period the amount of lead in petrol has changed little but general traffic flow has steadily increased; there has been no change in the amount of lead in water.
\end{abstract}

\section{Introduction}

Since 1972 the Medical Research Council Epidemiology Unit has conducted several surveys in Wales of blood lead concentrations $^{1-4}$ (P C Elwood, H F Thomas, unpublished report to the Welsh Office, 1973; P C Elwood et al, unpublished observations). After a report of a fall in blood lead concentrations in the United States between 1976 and $1981^{\circ} \mathrm{I}$ decided to examine changes in mean blood lead concentrations in these surveys. A further reason for this work was the finding that over the period covered by these surveys my blood lead concentration had fallen by $50 \%$.

\section{Method}

All the surveys reported here were based on representative samples of adult women, mostly random samples drawn from electoral rolls for defined areas. A high response rate was achieved, and blood samples were obtained from over $90 \%$ of the subjects selected for blood sampling in each survey. Venous blood samples were taken in all the surveys and were all analysed in the Supra-Regional Assay Service lead laboratory in Leeds. In most of the surveys duplicate blood samples taken from haphazard subsamples of subjects were also analy-

Medical Research Council Epidemiology Unit, Cardiff CF2 3AS P C ELWOOD, MD, FRCP, director sed in the Supra-Regional Assay Service laboratory in Southampton (formerly London) as part of an elaborate quality control scheme. Differences between these two laboratories were trivial in every survey, and reproducibility of estimates in both laboratories was good throughout.

The first survey (P C Elwood, H F Thomas, unpublished report to the Welsh Office, 1973) was based on a random sample of 30 women drawn from the electoral roll for a small seaside town in south Wales. This had been chosen as a "control" area for a study of heavy metal pollution in the south Wales valleys. "First draw" water samples were taken in 16 of these dwellings and all contained less than $0.1 \mu \mathrm{g} \mathrm{lead} / 1$ water.

The second survey ${ }^{1}$ was based on a sample of 1000 women drawn at random from the electoral rolls for the former county of Caernarvonshire. The women were asked to return an aliquot of a first draw domestic water sample, and 745 did so. Women whose water sample contained $0.1 \mu \mathrm{g}$ lead or more $/ 1$ water were selected together with a random sample of the others. This gave 109 women, and samples of venous blood were obtained from 104 of them. Blood samples were sent to both the Leeds and the London laboratories. The blood lead concentrations in these 104 women and the mean concentration in 71 women whose water sample contained less than $0 \cdot 1 \mu \mathrm{g} / 1$ are presented in this report.

The third survey ${ }^{2}$ was based on a random sample of women who lived in an area of old lead mining. Random samples were also drawn from electoral rolls for two areas well away from the area likely to be contaminated by lead spoil. Blood lead concentrations are presented here for the women in these two groups-that is, for 35 women in the control areas and, separately, for the random sample of 22 women in the contaminated area. The water supplies to all the areas in this survey were virtually lead free.

The fourth survey ${ }^{3}$ investigated a housing estate with high water lead concentrations. Only the results obtained in 54 women living in a neighbouring control estate in which all the samples of domestic water were found to contain less than $0 \cdot 1 \mu \mathrm{g} / \mathrm{l}$ are presented here.

A fifth survey (P C Elwood et al, unpublished observations) was based on the area contaminated by lead spoil studied in the second survey described above. A preliminary census was conducted and 58 children aged 1-3 identified. These were the subject of several investigations, but I present here the results obtained in their mothers, together with results for a random sample of women in the same area, 
giving a total of 138 women. As all these subjects lived in an area with lead contaminated soil I present their results only for comparison with the results from the similar group in the second survey. To interpret some of the findings in this particular survey, however, a control population of 33 children was selected in a village about 20 miles away in which there was no known source of lead. Results of blood lead estimations in the mothers of these children are also presented here.

The sixth survey ${ }^{4}$ was based on the mothers of a sample of 72 young children living in three valleys in south Wales. These had been included in a study of subjects living in close proximity to heavy traffic, but as there was no evidence of raised blood lead concentrations compared with the concentrations in the control village in the fourth survey above the results are included here.

A seventh survey (P C Elwood et al, unpublished observations) was conducted on residents in a town in west Wales. The intention was to study the effect on blood lead concentrations of hardening the water supply. As only one woman, out of the 95 seen in this survey, lived in a dwelling with a water lead concentration above $0.1 \mu \mathrm{g} / 1$ all the blood lead concentrations obtained in the preliminary survey, before the water supply was treated, are presented here.

The eighth survey (P C Elwood et al, unpublished observations) was based on a random sample of 517 women in three wards in Gwynedd. This survey was closely similar in design to the first survey described above and covered a substantial part of the area covered in that survey. After stratification on the basis of a preliminary sample of water 240 women were selected for the main study. Blood samples were sent to the Leeds lead laboratory; samples from a random subsample of 53 women were sent to the Southampton laboratory. The bulk water supply to the area covered by this survey had not changed since the first survey. Blood lead concentrations are also presented here for the 226 women whose water samples contained less than $0 \cdot 1 \mu \mathrm{g}$ lead/1 water.

\section{Results}

The figure and table show the mean blood lead concentrations in the various population samples. These means suggest that blood lead concentrations fell by over 30\% during 1974-82.

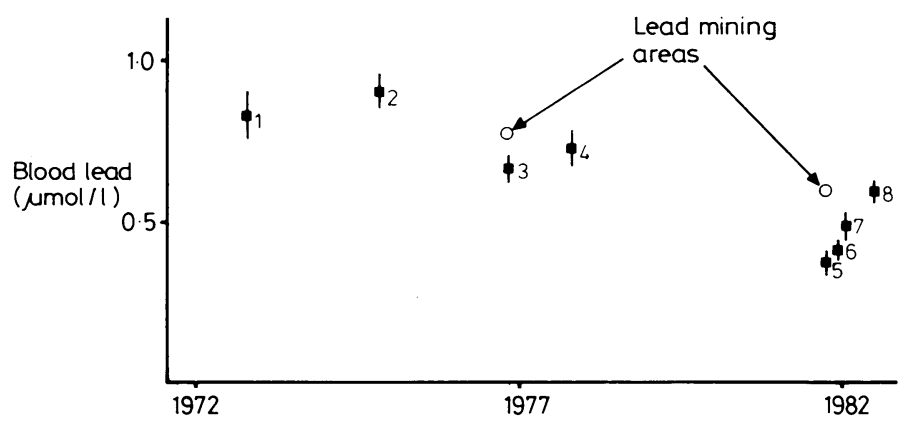

Mean blood lead concentrations in samples of women in Wales. Figures indicate number of survey referred to.

Conversion: SI to traditional units-Lead: $1 \mu \mathrm{mol} / 1 \approx 20 \cdot 7 \mu \mathrm{g} / 100 \mathrm{ml}$.

Details of surveys of blood lead concentrations in women in Wales

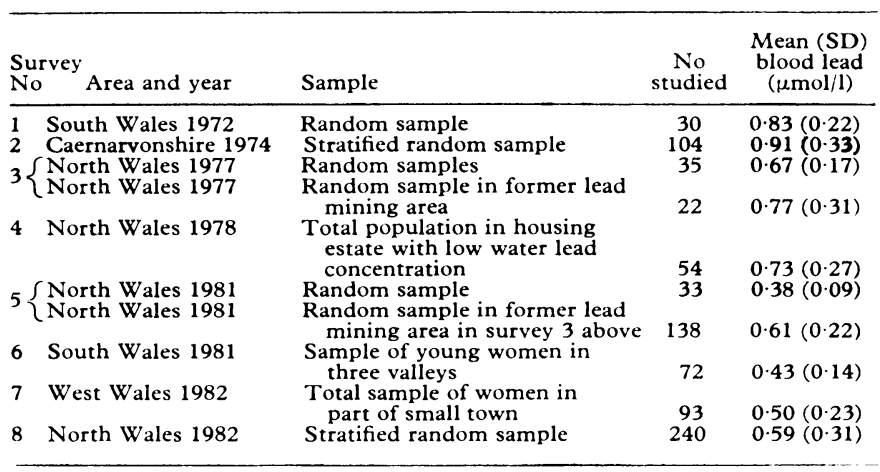

Conversion: SI to traditional units-Lead: $1 \mu \mathrm{mol} / 1 \approx 20 \cdot 7 \mu \mathrm{g} / 100 \mathrm{ml}$.
Two surveys (survevs 2 and 8 ) were conducted in the same area. Estimations in the Leeds lead laboratory showed that the mean blood lead concentration fell by $37 \%$ between 1974 and 1982 (table). Aliquots of all the blood samples taken in 1974 were also sent to the London lead laboratory, as were aliquots of a random sample of 53 blood samples taken in the 1982 survey. In this laboratory the mean was estimated to be 0.93 (SD 0.37$) \mu \mathrm{mol} / 1(19(8) \mu \mathrm{g} / 100 \mathrm{ml})$ in 1974 and $0.49(0.27)(\mu \mathrm{mol} / 1(10(6) \mu \mathrm{g} / 100 \mathrm{ml})$ in 1982 , a fall of about $47 \%$. Both these surveys were conducted as part of an investigation of blood lead concentrations in relation to water lead concentrations. In the first survey $4.3 \%$ of dwellings in the original random sample had had water lead concentrations of $0 \cdot 1 \mu \mathrm{g}$ or more/l, and in the 1982 survey $4.8 \%$ of dwellings had had water concentrations above this limit. The data suggested that water lead concentrations had not changed in the interval, but I nevertheless examined changes in women living in dwellings with water lead concentrations below $0 \cdot 1 \mu \mathrm{g} / \mathrm{l}$. Estimations in the Leeds lead laboratory yielded a mean in 71 such women in 1974 of $0.81(0.28) \mu \mathrm{mol} / \mathrm{l}(17(6) \mu \mathrm{g} / 100 \mathrm{ml})$ and in 215 women seen in 1982 of $0.56(0.28) \mu \mathrm{mol} / 1(12(6) \mu \mathrm{g} / 100 \mathrm{ml})$, representing a fall of $31 \%$. Again, when women in dwellings with water lead concentrations of $0.1 \mu \mathrm{g}$ or more/1 were excluded the blood samples sent to the Southampton (London) laboratory yielded a mean in 71 women seen in 1974 of $0.85(0.35) \mu \mathrm{mol} / 1(18(7) \mu \mathrm{g} / 100 \mathrm{ml})$ and in 48 women seen in 1982 of $0.47(0.26) \mu \mathrm{mol} / 1(10(5) \mu \mathrm{g} / 100 \mathrm{ml})$, equivalent to a fall of about $30 \%$

The two surveys conducted in the same former lead mining area (surveys 3 and 5) showed mean blood concentrations of $0.77(0.68)$ $\mu \mathrm{mol} / \mathrm{l}(16(14) \mu \mathrm{g} / 100 \mathrm{ml})$ in 1976 and $0.61(0.22) \mu \mathrm{mol} / 1$ (13 (5) $\mu \mathrm{g} / 100 \mathrm{ml}$ ) in 1981 , a fall of $21 \%$. While these means were not comparable with those for the other population samples, they were comparable with each other, and no correction for water lead concentration was necessary as the area had a virtually lead free water supply.

\section{Discussion}

These data suggest that blood lead concentrations in women fell substantially in Wales between 1974 and 1982. The size of the fall was remarkably similar to that described in the United States, where it has been linked with changes in lead in petrol.

The data presented here have limitations, the most important being the possibility of drift in the laboratory. The fact that a second control, lead laboratory was used in this study gives some reassurance, but as all the laboratories run their own internal quality control scheme it is just possible that they would all drift together, though this is highly unlikely.

Further limitations arise because the evidence is based on several different groups of women examined at different times rather than a single group followed up over time. All the surveys, however, were of representative population samples. Most of these samples were small, but their size had been carefully chosen in relation to the various hypotheses tested; it can be shown that samples of about 30 adults, provided they are chosen in a way that ensures representativeness, are sufficient to detect differences or changes in mean blood lead concentration of around $20 \%$ or more.

During the period of these surveys the amount of lead in petrol in the United Kingdom fell, but this was probably balanced by an increase in petrol consumption. ${ }^{6}$ Lead in paint is an important source of lead in some children but is probably of little importance in adults. Changes in water lead concentrations are more difficult to assess. While there was no change in the bulk supplies that might have affected any of the results presented here, lead pipes were removed from several dwellings during the period covered by this study, mainly in the area covered by surveys 1 and 7 . While the number of dwellings so affected was probably quite small, the change is likely to have occurred preferentially in dwellings with high water lead concentrations. To make some allowance for this it was necessary where appropriate, to present separately blood lead concentrations in women in dwellings with water lead concentrations below $0 \cdot 1 \mu \mathrm{g} / 1$.

The effect of changes in lead in food are also difficult to assess. No attempt was made in any survey to assess the dietary intake 
of lead. Data from the Ministry of Agriculture, Fisheries, and Food, ${ }^{7}{ }^{8}$ however, suggest that there has been a substantial reduction in lead in most foodstuffs since 1970, and the mean dietary intakes of many foodstuffs have changed. ${ }^{9}{ }^{10}$ These data have led to estimates of daily lead intake from food ranging from about $200 \mu \mathrm{g} /$ day per adult in $1970-2^{7}$ to about $100 \mu \mathrm{g} /$ day per adult towards the end of the 1970 s. $^{8}$ While these estimates are crude, the increase in the use of frozen foodstuffs and the fall in the use of tinned foods, together with improved canning methods and other changes in the food industry, must have led to substantial reductions in lead intake from dietary sources.

An association exists between the hardness of domestic water and blood lead concentrations, and it has been suggested that hard water, even in the absence of water lead, may lower the absorption of lead from other sources." Recent surveys carried out (surveys 7 and 8; P C Elwood $e t$ al, unpublished observations) represent the first phase of longitudinal studies of the effect on blood lead concentrations in residents of hardening soft plumbosolvent water in two areas. The changes in blood lead concentrations that the surveys reported here suggest occurred during a period when no changes were made in the water supply and show the need for controlled and carefully designed studies to evaluate any measure aimed at reducing blood lead concentrations. Indeed, in view of the fall in blood lead concentrations detected during a period in which no appreciable reduction occurred in the lead content of petrol it may well prove difficult to detect any effect on blood lead concentrations of lowering exposure to environmental lead in this way.

I am grateful to the many people who played a part in these surveys, in particular Dr C Toothill, Dr P Broughton, and Dr H T Delves, of the Supra-Regional Assay Service lead laboratories; the chemists and others in the laboratories of the Welsh Water Authority; and Dr M Morton, of Tenovus Institute, Cardiff.

\section{References}

${ }^{1}$ Elwood PC, St Leger AS, Morton M. Dependence of blood lead on domestic water lead. Lancet 1976; : 1295.

${ }^{2}$ Thomas HF, Moore F, Welsby E, Elwood PC, Firth JNM. The hazard of old lead mines in Wales. British fournal of Preventive and Social Medicine $1977 ; 31: 265-8$.

3 Thomas HF, Elwood PC, Welsby E, St Leger AS. Relationship of blood lead in women and children to domestic water lead. Nature 1979;282 712-3.

${ }^{4}$ Elwood PC, Gallacher J, Toothill C. Lead in petrol. Br Med $\mathcal{f} 1982$;284: 1189.

${ }^{5}$ Center for Disease Control. Blood lead levels in the US population. $M M W R 1982$ Mar $31: 132-4$.

- Working Party on Lead in the Environment. Lead and health. Report. London: HMSO, 1980.

${ }^{7}$ Ministry of Agriculture, Fisheries, and Food. Survey of lead in food. London: HMSO, 1975.

${ }^{8}$ Walters B, Sherlock J. Studies on the dietary intake of heavy metals. International conference on heavy metals in the environment, Amsterdam, 1981. London: HMSO, 1982:506-12.

${ }^{9}$ Ministry of Agriculture, Fisheries, and Food. Household food consumption and expenditure 1970. Annual report of the National Food Survey Council. London: HMSO, 1973:68-73.

${ }^{10}$ Ministry of Agriculture, Fisheries, and Food. Household food consumption and expenditure 1979. Annual report of the National Food Survey Council. London: HMSO, $1981: 30-2$.

11 Thomas HF, Elwood PC, Toothill C, Morton M. Blood and water lead in a hard water area. Lancet $1981 ; \mathrm{i}: 1047-8$.

(Accepted 8 February 1983)

\title{
Use of the "Scotchcast boot" in treating diabetic foot ulcers
}

\author{
A C BURDEN, G R JONES, R JONES, R L BLANDFORD
}

The pathogenesis of diabetic foot ulceration includes peripheral and autonomic neuropathy, vascular abnormalities, infection, and trauma. Healing is helped by reducing pressure on the affected foot in bed or with a plaster of Paris cast with a window cut out over the lesion. ${ }^{1}$ These casts are, however, heavy and fragile when wet, needing frequent reapplication. We investigated the use of a Scotchcast (3M UK Ltd, Loughborough, Leicestershire) as a substitute for plaster of Paris because of its lightness and high integral strength.

Diabetic Unit, Leicester General Hospital, Leicester LE5 4PW

A C BURDEN, MD, MRCP, consultant physician

G R JONES, MB, MRCP, senior registrar

R JONES, SRN, plaster room sister

R L BLANDFORD, $M B, M R C P$, senior registrar

Correspondence to: Dr G R Jones.

\section{Patients and methods}

All 58 patients presenting to the diabetic clinic at this hospital with foot ulceration between February 1979 and February 1982 were studied. After vascular assessment 18 patients were excluded because they had operable disease. The remaining 40 patients formed the study population. Of these, 11 had distal vessel disease, typified by absent pulses below the femoral arteries; the other 29 had palpable popliteal pulses and at least either a dorsalis pedis or posterior tibial pulse present. Twenty seven patients had solitary lesions on the sole, six solitary lesions on the heel (fig 1), five lesions on both the sole and the toe, and two combined heel and sole lesions.

Optimum diabetic control was achieved in these patients, and if infection was evident broad spectrum antibiotics were given intravenously for five days and subsequently by mouth for up to three months. Ulcers with large areas of necrosis were surgically debrided. Wounds were dressed either with non-stick dressings (Melolin; Smith and Nephew Ltd, Birmingham) after local toilet or packed with dilute hypochlorite solution (Milton) and ribbon gauze. A Scotchcast boot was fashioned with a window cut out over the ulcer to allow dressings to be renewed; the boot was changed each month. Dressings were reapplied as required, and patients were regularly supervised at the foot clinic.

When the ulcers had healed "space shoes" were fitted (Lane Orthopaedics Ltd, Northampton). These are high volume shoes made with 